\title{
Examination of suitability of performance based contracts for the Turkish road maintenance sector
}

\author{
Koray Ateş ${ }^{\text {iD }}$, Güzide Atasoy ${ }^{\text {iD }}$, Hande Işı1k Öztürk* ${ }^{*}$ \\ Middle East Technical University, Department of Civil Engineering, Ankara, Turkey
}

\begin{abstract}
Over the last decades, many countries have been in the search of new contracting types for the road maintenance sector to increase the efficiency and to reduce the cost. Lately, Performance based Contracting (PBC) became a popular approach for road maintenance (RM). Although there are many studies and cases that present the affirmative results of $\mathrm{PBC}$, changing the RM system from the traditional contracting methods to $\mathrm{PBC}$, is very compelling. Turkey has made huge investments in road construction sector and maintenance activities in recent years. These investments will lead to excessive road maintenance costs in the near future. Moreover, sustaining the quality of road networks can be a challenge. PBC is known to be very promising to maintain the road network on a permanently good level of service. However, based on the existing conditions and expectations of each country, a custom PBC system needs to be established. Hence, the objective of this study is to acquire the perspectives of road users and experts on the quality of the existing RM services and their expectations. Moreover, it was aimed to examine the perspective of experts to the current contracting method and PBC. For this purpose, three interviews were performed with senior road experts, and two sets of surveys were designed. The first survey targeted road users and the second survey targeted road experts from different stakeholders (e.g., designers, consultants, road agency). Consequently, the majority of participants stated that the current RM services require improvement and $\mathrm{PBC}$ has the potential to address this need.
\end{abstract}

\section{Keywords}

Road maintenance; Snow and ice removal; Contract; Performance based contracting; Turkish road sector

Received: 22 July 2020; Accepted: 14 September 2020

ISSN: 2630-5771 (online) (C) 2020 Golden Light Publishing All rights reserved.

\section{Introduction}

Road networks are accepted to be an essential public asset of the counties [1]. Hence, road maintenance and rehabilitation should be taken into account seriously via strategic planning and scheduling. If not, many governmental and research studies reveal that it has negative impacts on the economy and road safety. According to a study covering 85 countries, the reconstruction cost of a road is about three to four times higher than the cost of well-planned maintenance and rehabilitation actives through the life of the pavement [2].

Road authorities are responsible for the maintenance of their road network identifying strategies and methods without compromising the quality and safety of their network. Thus, with the expansion of the global roadway networks and aging of the existing roadway networks, road authorities are working on new contracting methods to increase efficiency and to reduce the cost and

\footnotetext{
Corresponding author

Email: ozturkha@metu.edu.tr
} 
liability of the Agency since the 2000s [3]. This need has arisen from the disadvantages and limitations of conventional contracting. Lately, Performance Based Contract (PBC), which is a popular contracting method for many sectors, including the defense, energy, shipping, and manufacturing sectors, is also assimilated for road maintenance contracts. Many developed countries have already adopted their road maintenance contracts, according to PBC [4]. Moreover, many developing and undeveloped countries are also applying or performing case studies on PBC.

In Turkey, the General Directorate of Highway (GDH) is the authority responsible for the maintenance and rehabilitation of highways and motorways, since 1948. Till 2013, all the work was handled in-house by its own employees using its own equipment park. After 2013, GDH has tendered road maintenance services to the private sector with method-based contracting (except the Build Operate and Transfer projects) depending on the amount of work done. Accordingly, payments are based on a mutually agreed unit rate with the specified methodology. Routine maintenance services in Turkey are executed under methodbased contracting in lumpsum, but snow and ice removal works are implemented as unit price [5]. Gun (2014) [6] conducted a survey targeting GDH's employees to examine their perspective on PBC for road maintenance (RM) services. The study reflected the positive attitude of the GDH towards PBC. However, viewpoints and comments of all stakeholders (e.g., road user, contractor, client, and designer) must be consulted to understand the current status of RM services in Turkey, and to identify the necessary improvements in RM services with a holistic view. Otherwise, approaches based on a single perspective may fail to reveal the problematic issues (e.g., payment plans). In this case, the solutions may work out only for the benefits of a single party.

Hence, the primary objective of this study is to investigate the RM services in Turkey and to examine the applicability of PBC for the Turkish RM sector. Therefore, the first research question of this study is, "What is the status of road maintenance services in Turkey?". The second research question is, "What is the potential impact of transitioning from conventional contracting to PBC on RM services?". To answer these questions, road maintenance data regarding the regulations and tenders were examined; interviews and surveys with road users and road experts were performed. The following sections include a brief literature review on PBC for RM services, the methodology and findings of the interviews and surveys, and the conclusion of this study.

\section{Literature review}

Road maintenance and rehabilitation activities can be carried out either in-house or by the private sector. On a global scale, the in-house approach is being replaced by outsourcing and contracting more and more [1]. According to Zietlow [7], shifting to the private sector resulted in a decrease in the cost of $\mathrm{RM}$ services in the range of $30 \%$ to $50 \%$. Countries such as Finland, Western Australia, Canada (Alberta, British Columbia, Ontario), Norway, Holland, England, and New Zealand only prefer to award the road maintenance projects to the private sector. Whereas, some other countries (e.g., Estonia, Turkey) still prefer to use both in-house and contracting, based on the type of work [8].

Although there are various conventional and contemporary project delivery systems, PBCs are becoming popular in both developed and developing countries, for road maintenance. $\mathrm{PBC}$ is a procurement system where the payments are made based on the measured outcome (performance) and timeline of the work rather than the quantity. In 1988, the first PBC was implemented in British Columbia, Canada. Then, Argentina signed a PBC contract for a $1000 \mathrm{~km}$ roadway [9]. In the 1990s, a Road Rehabilitation and Maintenance Contracts program, known as CREMA, was initiated for Latin American countries such as Uruguay, Chile, Brazil, and Peru. Around the same time, developed counties such as the United States, Australia, Denmark, Estonia, and Finland also started to develop their own PBC programs. World Bank, as an international finance agency, supported the first 
PBC contract in 2002. Since then, $200 \mathrm{PBC}$ projects were supported by the World Bank [10].

In $\mathrm{PBC}$, performance indicators and outputs are the key characteristics rather than the inputs, activities, and methodology [11]. Therefore, the performance indicators should be carefully set, taking into account the challenges, the inventory on current road conditions, roadside facilities, geographical conditions, the needs of the road users, the expectation of the clients, and affordability $[12,13]$. It should also be noted that these indicators originate from the practices and the experiences of the authorities, thus vary from country to country. The quality of the implemented work is better as compared to the other contract types, since the payments depend on the performance indicators, not the quantity of the work. Therefore, the indicators should be clearly defined including their response times, and easily and transparently measured by the client $[13,14]$. Moreover, in PBCs, the risk shifts from the Agency to the contractor, though the risk from unexpected conditions such as inflation, climatic changes, political uncertainties should be handled by both parties. Besides, the duration of PBC is considerably longer at a range of 3 to 10 years and even up to 30 years [15]. Therefore, the Agency should ensure that the contractor can handle the project including its cost, risks, and management to achieve the performance indicators within the timeline.

PBC provides several advantages in terms of cost savings [9, 10,13,16,17, 18, 19], use of innovative and efficient methods [1, 13], staffing [13, 18], user satisfaction [13], and traffic and safety [14]. On the contrary, it also has its challenges and drawbacks such as long-term contract duration, continuity in funding, selection of the right contractor, legislations and regulation, ability and expertise of the staff, asset management, determination of the penalties, warranties, and guaranty [1, 9, 20, 21]. After the evaluation of these advantages and disadvantages of $\mathrm{PBC}$, it was concluded from the literature review that $\mathrm{PBC}$ is significantly promising for both developed and developing countries to maintain the road network on a permanently good level of service. However, each country should adapt PBC according to their existing conditions and expectations. Hence, this study was designed to provide valuable insights on the quality of the existing RM services and the expectations of the road users and road experts from different perspectives.

\section{Methodology}

This study includes interviews and surveys to examine the existing status of road maintenance (RM) services in Turkey and the potential of PBC in the sector. A detailed literature review was performed to identify the characteristics, advantages, disadvantages, challenges, performance indicators, and legal procedures of PBC. Using data acquired from the literature review, an interview protocol was prepared. According to the responses from the interviews and inferences from the literature review, two separate surveys, targeting road experts and road uses, were prepared. Approval was received from the Human Subjects Ethics Committee of METU (No. 350 ODTÜ 2019). These user and expert studies were assessed to examine the existing RM services in Turkey and to evaluate the perceptions of various stakeholders (e.g., GDH, consultants, designers) towards PBC.

\subsection{Data Collection}

To find out the structure, scope, and performance of RM services in Turkey, reports, specifications, regulations, manuals, and current public procurement law were reviewed. In addition, road maintenance projects tendered to the private sector in the last five years (2015-2019) were analyzed to understand the strategy of the procurement system in Turkey. In order to acquire the experiences of countries that implement PBC in RM services, the lessons learned, characteristics and case studies shared by these countries were summarized and synthesized. Ates (2019) [22] contains the details of these analyses on Turkey and PBC applications. Then the synthesized information was utilized to develop the interview and survey questionnaires. 


\subsection{Interviews}

To evaluate the scope and implementation of road maintenance works in Turkey; three experts, having wide knowledge in RM services, were interviewed. Selecting the interviewees from three different stakeholders (road authority, construction firm and consultancy firm) enabled obtaining perspectives from different angles.

Within the interview, eleven questions (See Table 1) were asked to these experts (See Table 2). First five questions were related with the demographics of the participants. Following six open-ended questions were designed to understand the current situation of the regulations and procedures regarding RM services in Turkey, and to understand the suitability and applicability of PBC for the Turkish RM sector. The shortcomings of the current procedures and the potential changes were identified by the participants. The interviewees' comments were collectively analyzed and integrated to determine the questions to be asked in the surveys.

\subsection{Surveys}

After the initial examination of the data collected from the literature review and interviews; two types of surveys were prepared to answer the research questions. A commonly used web-based software tool, Surveymonkey, is used to perform the surveys.

Table 1. Interview questions

\begin{tabular}{ll}
\hline$\#$ & Questions \\
\hline 1 & Your age \\
2 & Graduation year and department \\
3 & Years of experience in the road sector \\
4 & International experience regarding road maintenance \\
5 & Current position, title and institution \\
6 & When and how should the maintenance need of the existing roads be identified? \\
7 & Should the road maintenance works be performed by the Agency (KGM) or private companies? \\
8 & What are the technical and managerial shortcomings of the current method-based maintenance services in \\
9 & $\begin{array}{l}\text { Turkey? Do you have any suggestions to address these shortcomings? } \\
10\end{array} \quad \begin{array}{l}\text { Do you think applying PBC in Turkey can address the problems you identified? } \\
11\end{array} \quad \begin{array}{l}\text { What is the applicability of the fundamental characteristics of PBC (flexibility in the methods, long-term } \\
\end{array} \quad$\begin{tabular}{l} 
contracting, incentives and disincentives, performance indicators and their application) to Turkish road \\
\hline
\end{tabular}
\end{tabular}

Table 2. Profile of experts working in road sector is summarized in the following table.

\begin{tabular}{|c|c|c|c|c|c|c|c|}
\hline \multirow[b]{2}{*}{ No } & \multirow[b]{2}{*}{ Expertise } & \multirow[b]{2}{*}{ Profession } & \multirow{2}{*}{$\begin{array}{c}\text { Total } \\
\text { Experience }\end{array}$} & \multirow{2}{*}{$\begin{array}{c}\text { Experience } \\
\text { in Road } \\
\text { Sector }\end{array}$} & \multirow[b]{2}{*}{ GDH } & \multicolumn{2}{|c|}{ Private Sector } \\
\hline & & & & & & $\begin{array}{l}\text { Consulting } \\
\text { firm }\end{array}$ & $\begin{array}{l}\text { Construction } \\
\text { firm }\end{array}$ \\
\hline 1 & $\begin{array}{c}\text { Supervision } \\
\text { Engineer }\end{array}$ & $\begin{array}{l}\text { Civil } \\
\text { Engineer- } \\
\text { B.Sc. }\end{array}$ & 38 years & 29 years & - & 29 years & \\
\hline 2 & $\begin{array}{l}\text { Contract } \\
\text { Engineer }\end{array}$ & $\begin{array}{l}\text { Civil } \\
\text { Engineer- } \\
\text { B.Sc. }\end{array}$ & 27 years & 26 years & 22 years & 2.5 years & 2.5 years \\
\hline 3 & $\begin{array}{l}\text { Quality - } \\
\text { Control } \\
\text { Engineer }\end{array}$ & $\begin{array}{c}\text { Civil } \\
\text { Engineer- } \\
\text { M.Sc. }\end{array}$ & 49 years & 34 years & 28 years & - & 6 years \\
\hline
\end{tabular}


The first survey (hereinafter referred as Survey1) consisting of 14 questions was prepared to gather perceptions of road users in Turkey. The participants were reached using social media and sending e-mails to firms, foundations, and public \& private sector. The aim of Survey-1 was to understand the level of satisfaction of passengers and drivers about RM services in highways and motorways. Although the sample size was calculated as minimum 666 people in respect of the target population [23], 1036 people from all strata were reached within 20 days.

The second survey (hereinafter referred as Survey-2) consisting of 16 questions was prepared for the road experts from the RM sector working in Public Authorities, Associations, Contractors, Consultants. The aim of Survey-2 was to analyze the existing status of RM sector, to identify the areas of improvement, to evaluate PBC in RM services upon their experiences, and to find out awareness and need for Asset Management Systems. To acquire a holistic view from all stakeholders, target experts were chosen with respect to their expertise and knowledge. A total of 100 emails were sent to professionals with the link of the survey and a short description of the objective of the study. A total of 68 experts participated in Survey-2.

Survey questions were mainly composed of two sections. Demographics part collected information regarding the age, occupation, and experience of the participants. These questions used multiple choice answers. The other part of the surveys used Likert scale (agree, partially agree, not agree, no comment) and multiple-choice questions. These questions went through iterations by the research group and the initial three interviewees to ensure that they were easily understandable, to-the-point, and not time-consuming.

\section{Findings}

In the findings section, initially, the interviewees' perspective on current RM services, Snow and Ice Removal (S\&IR) Works, and PBC in RM services was presented. Accordingly, the surveys that were based on the results of these interviews are discussed to reflect the perception of participants towards (i) the current RM services and (ii) applicability of PBC in Turkey.

\subsection{Interview}

The comments and suggestions of the three interviewees were synthesized according to the answers given to each question in Table 1. The summary of the comments is presented in Table 3. This summary table indicates the major shortcomings of the current RM services that resulted from the short-time nature of the contracts jeopardizing innovative approaches, high quality works, and long-term investments. In addition to these, the challenges of S\&IR works were arisen from unclear/ vague requirements and resource assignments. Moreover, the need for clear payment, incentive, and disincentive system, and procedural and legislative changes were highlighted. The outputs of these interviews were utilized to design the survey questions in addition to the output of the literature review.

\subsection{Survey 1}

A total of 1036 participants completed the survey with an average completion time of three minutes and 18 seconds. The results reflect the thoughts of participants, who indicated that they were using the road network as both as drivers (95\% of the participants had driving licenses), and passengers. Fig. 1 (a through e) depicts the participant profile, including the age distribution, education status, region they live in, regions they travel to, and their travel frequency.

Fig. 1 reveals that participants' profiles had a wide range of variations in terms of age, educations level, and travel habits. Additionally, participants were living in all regions of Turkey and traveled to many different regions in the last 5 years. In this way, results covering different road networks in Turkey were gathered.

The most effective and easiest way to understand whether RM services in a country are performed properly or not, is the assessment of user satisfaction [4]. 
Table 3. Summary of the Interviews

Summary Table for Comments of Interviewees

Current RM services;
The decision on RM projects to be
tendered is taken in a very short time.

Each work item in specification should be defined clearly and in detail.

No possibility to use innovative approaches in RM services under the current legislative regulations

Short-term contracts in RM services does not allow the private sector to provide qualified staff and procure all the necessary machinery and materials

Short-term contracts in RM services does not allow private sector to make necessary investments and to complete the project properly
Current S\&IR works:

Short-term contracts in S\&IR services does not allow private sector to make machinery investments

The quantity and conditions of the work to be performed is not clear. It depends on winter conditions. Therefore, it should be scheduled in every year in the long-term.

The payment method is not clear under the condition that the machines / personnel are idle

Machinery, staff and payment conditions should be rearranged by itself in case of excessively snowy seasons

All penalties imposed to the contractor should be defined in clearly if services are not performed

\section{$\mathrm{PBC}$ in $\mathrm{RM}$ services}

Contractor should define method applied during implementation of contract in bidding phase for review and recommendation of the client

Budget and payment issues should be clarified in the beginning of long-term contract

Incentives and disincentives system should absolutely be applied to the RM contracts

Performance criteria should certainly be included in the RM contracts and defined according to type of road (state highway, motorway, etc.)

S\&IR works should be executed by both private sector and road authorities to provide road safety with highest level.

The current procurement law, budget/payment conditions and type contracts should be modified to adapt the PBC and transition term should be planned very carefully.
Thus, the effectiveness and regularity of RM and S\&IR services in Turkey were asked to road users for their evaluation. In Figure 2a, Survey-1 results are summarized with respect to three essential questions, whether RM services are carried out regularly, RM services carried out efficiently, and S\&IR works are carried out efficiently. Dissatisfaction rates were higher especially in regularity and effectiveness of RM services. On the other hand, the satisfaction and dissatisfaction levels of S\&IR services, which were usually carried out under RM services, were closer to each other. Therefore, further analysis was applied to the responses of the participants from regions with frequent snows in Turkey to obtain problemfocused results for S\&IR services. However, no clear distinction could be observed for that sample as well.

The participants traveling frequently were assumed to have a high probability to observe difficulties and deficiencies in road conditions and probability to observe RM activities during the execution. Thus, insightful feedback could be obtained from these participants when compared to other participants. The answers of 126 participants traveling frequently were also analyzed separately and presented in Figure 2b. After the comparison of results between all participants and frequent travelers, the trend in responses was observed to be similar to each other. Indeed, the dissatisfaction rates of frequent travelers were approximately 5\% higher for RM services. 


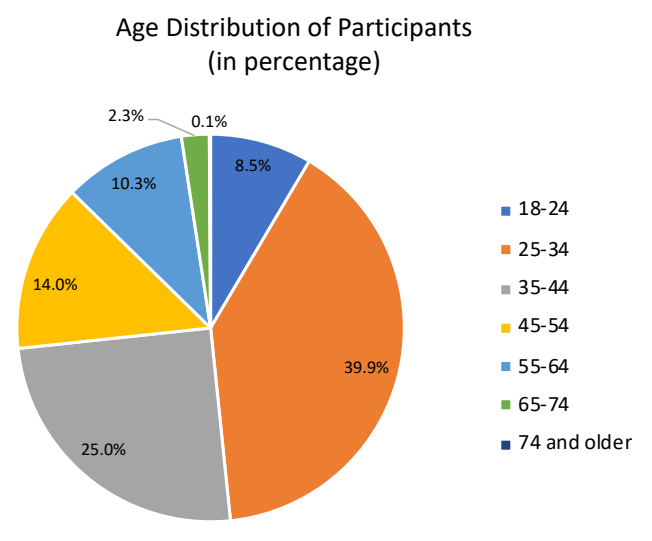

a. Age distribution

The Regions Participants Live (in number)

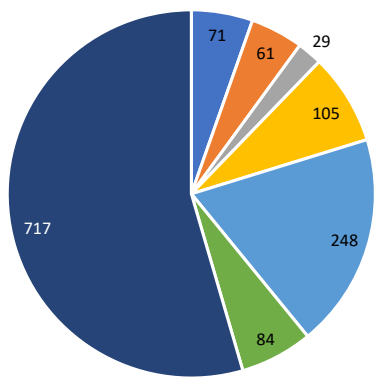

- Mediterranean

Eastern Anatolia

Southeastern Anatolia

- Aegean

- Marmara

- Black Sea

- Central Anatolia
Education Status of Participants

(in percentage)

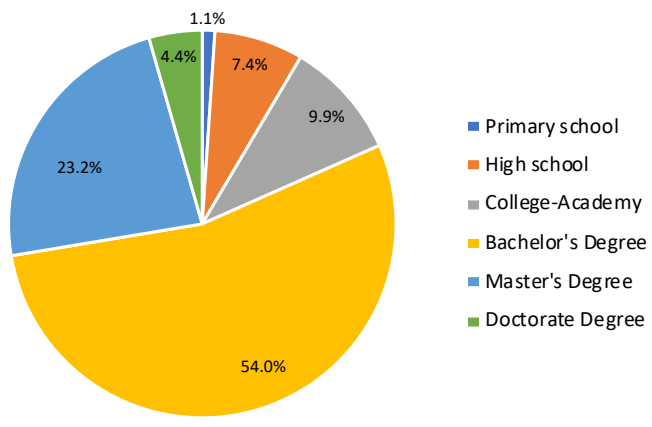

b. Education status

The Regions Participants Traveled in the Last Five Years (in number)

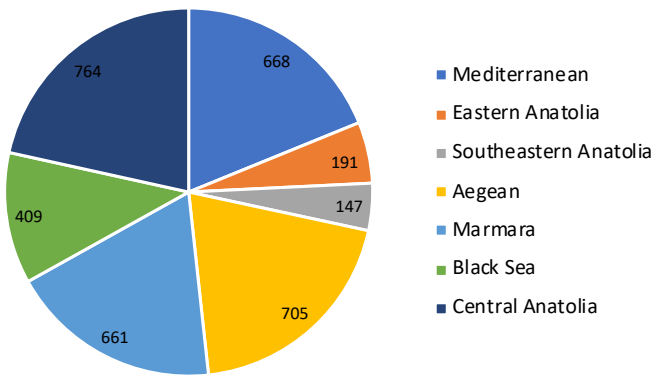

c. Regions resided

d. Regions traveled

Travel Frequency of Participants (in percentage)

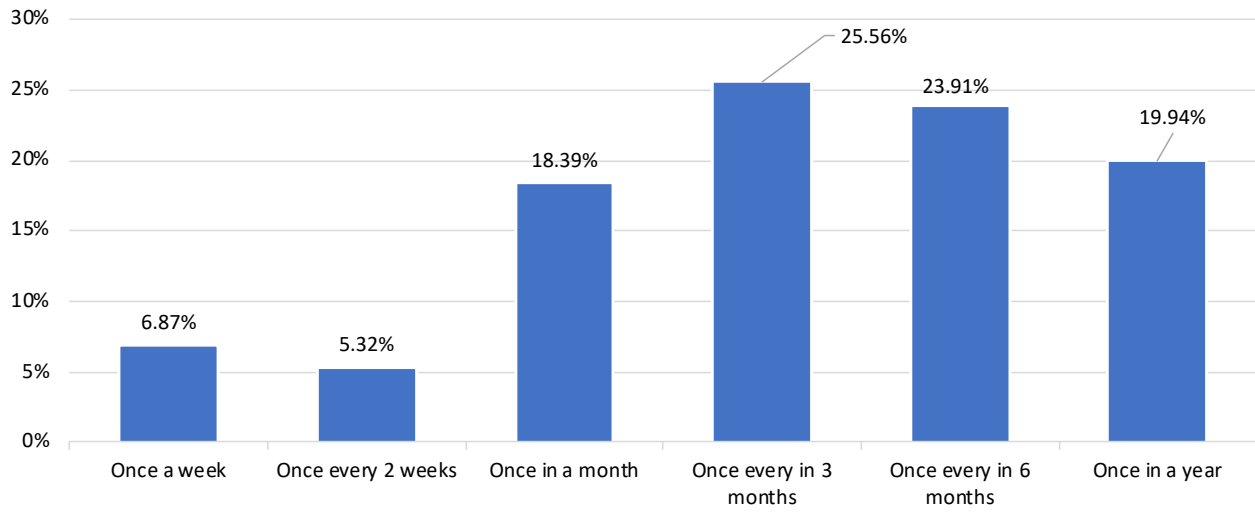

e. Travel Frequency

Fig. 1. Demographics of the participants of survey-1 
ALL PARTICIPANTS (1036)

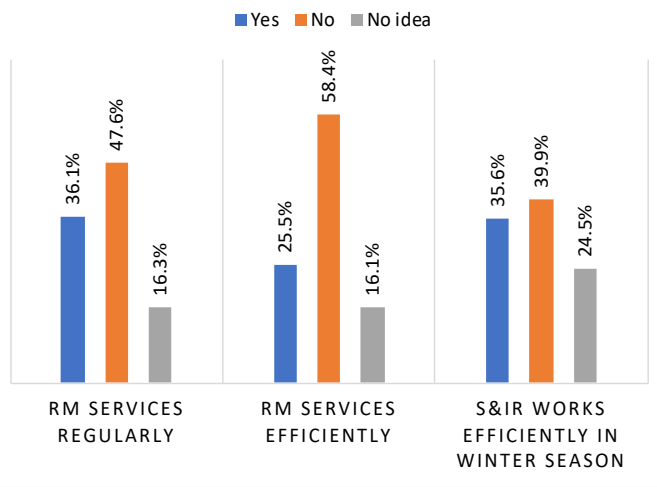

a. All participants
FREQUENT TRAVELERS (126)

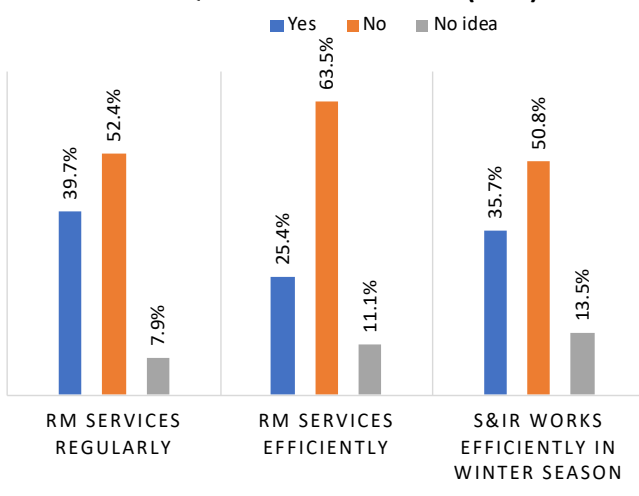

b. Frequent Travelers

Fig. 2. Efficiency and Regularity of RM Services and S\& IR Works

Additionally, all participants were asked to assess the impacts (e.g., decreased travel comfort, increased fuel consumption) if RM services were not executed regularly and efficiently. The percent distribution of the answers on a 5 Likert Scale was presented in Fig. 3.

As expected, the majority of the participants believed that these seven negative impacts have a high probability to happen. Indeed, $80 \%$ of participants agreed that improper RM services decrease the road safety and it is very crucial for the passenger and driver (P\&D) safety. On the other hand, delayed and improper RM services usually cause an increment in the cost of services. However, it was revealed that participants are not aware of this issue and disregard costly RM services.

Consequently, this survey showed that, overall, road users as passengers and drivers are not satisfied with current RM services in Turkey. Since the number of participants in our sample was well over the sample size threshold and the data acquired from these participants were consistent, it could be concluded that the results obtained from the survey reflect the perception about the current status of RM services and highways in Turkey.

\subsection{Survey 2}

A total of 68 experts, working in road projects under different parties, participated in Survey-2 within 30 days, and the average completion duration was 25 minutes and 18 seconds. The profile of road experts was summarized in Fig. 4.

Different viewpoints of stakeholders were very important in this study. For this reason, experts from various parties were involved in the survey, as shown in Fig. 4c. Besides, Fig. 4d presents that $65 \%$ of road experts who participated in the survey had more than 15 years of experience.

In this survey, participants were asked to evaluate the performance of current RM services (see Fig. 5) in terms of whether it is good, bad, and satisfactory but still has the potential to be improved, or no comment. The majority of the road experts' perspectives for all features (e.g., road quality and capability of contractors) were $\mathrm{bad} / \mathrm{improvable}$, except for road safety. The general overview of the participants reflected that the current services are not completely adverse, on the contrary, it is satisfactory or good. However, the majority of the participants highlighted the need and room for changing and developing current services, to remedy the shortcomings.

The participants were also asked to evaluate the potential effect of PBC on the RM services. The basic characteristics of PBC were summarized at the beginning of the survey for the road experts, who might not be familiar with this contract type. Three questions were prepared to evaluate the effects of the main characteristics and features of $\mathrm{PBC}$, which distinguish PBC from other contract types. These criteria and the results are presented in Fig. 6. 


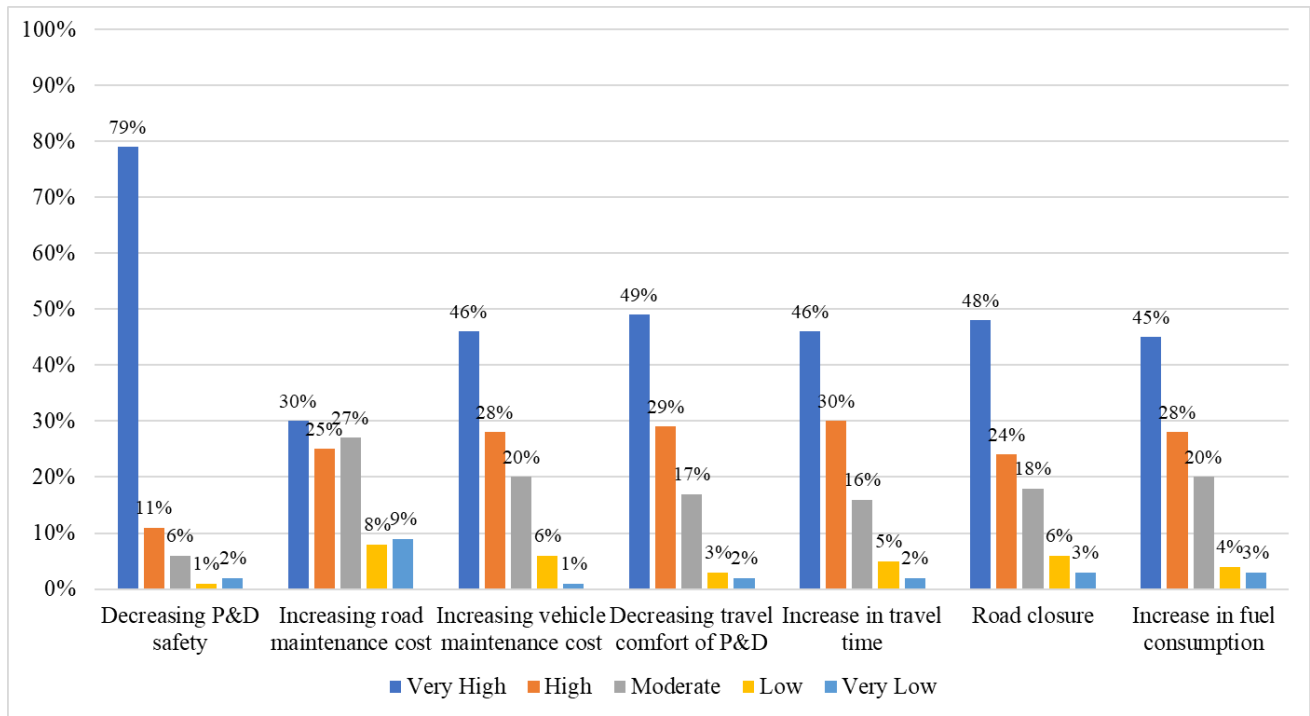

Fig. 3. Effects of Irregular and Inefficient RM Services

Age Distribution of Road Expert (in percentage)

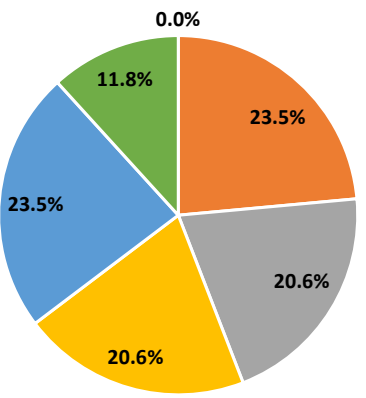

a. Age distribution

Type of institution Road Experts work (in number)

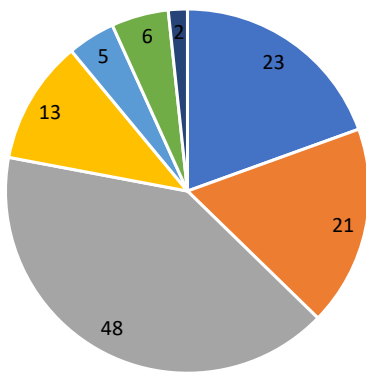

- General Directorate of
Highways
- Contactor
- Engineer / Supervision
- Design Firm
- Other Public Institution
- Consultancy Firm

c. Type of institution

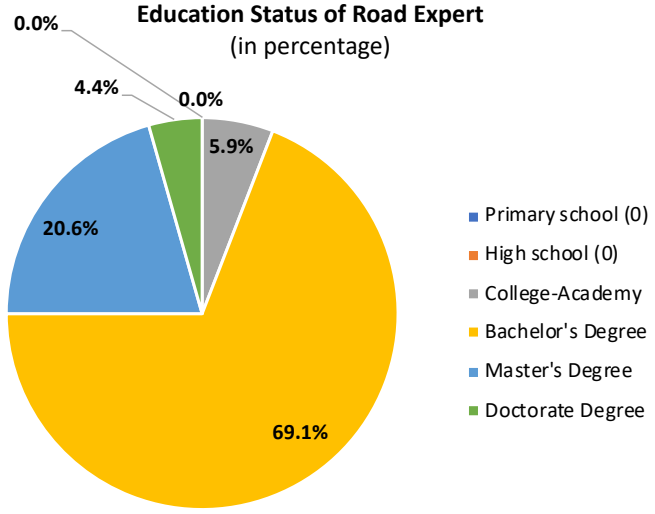

b. Education status

Total experience of Road Expert (in number)

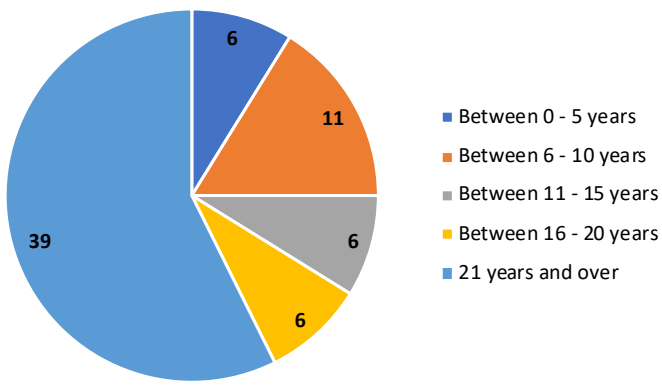

d. Years of experience

Fig. 4. Demographics and Backgrounds of the Participants of Survey-2 
Road Quality

Capability of Contractors

Procurement System

Risk sharing btw the parties

(2)

\begin{tabular}{|c|c|c|c|}
\hline $20,59 \%$ & $8,82 \%$ & $69,12 \%$ & $1,47^{\circ}$ \\
\hline $19,70 \%$ & $13,64 \%$ & $56,06 \%$ & $10,61 \%$ \\
\hline
\end{tabular}

\begin{tabular}{|c|c|c|c|}
\hline $16,42 \%$ & $28,36 \%$ & $41,79 \%$ & $13,43 \%$ \\
\hline
\end{tabular}

Utilization of technological developments

\begin{tabular}{|c|c|c|c|}
\hline $32,35 \%$ & $14,71 \%$ & $51,47 \%$ & $1,47 \%$ \\
\hline
\end{tabular}

User Satisfaction

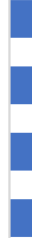

Effect on Project Cost

Effect on Road Safety

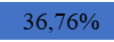

$20,59 \%$

$41,18 \%$

$1,47 \%$

$\begin{array}{llll}25,37 \% & 20,90 \% & 41,79 \% & 11,94 \%\end{array}$

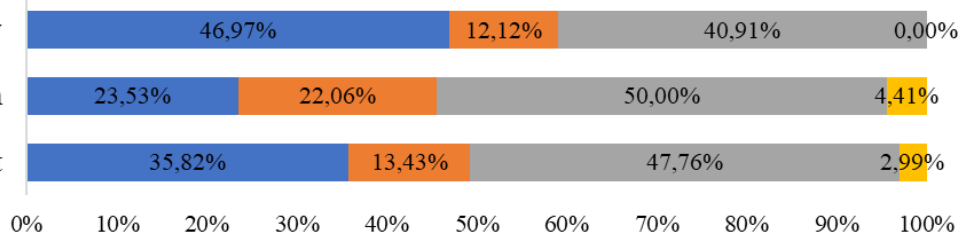

affirmative $\square$ Adverse Improvable $\backsim$ No Idea

Fig. 5. Existing status of the road maintenance services

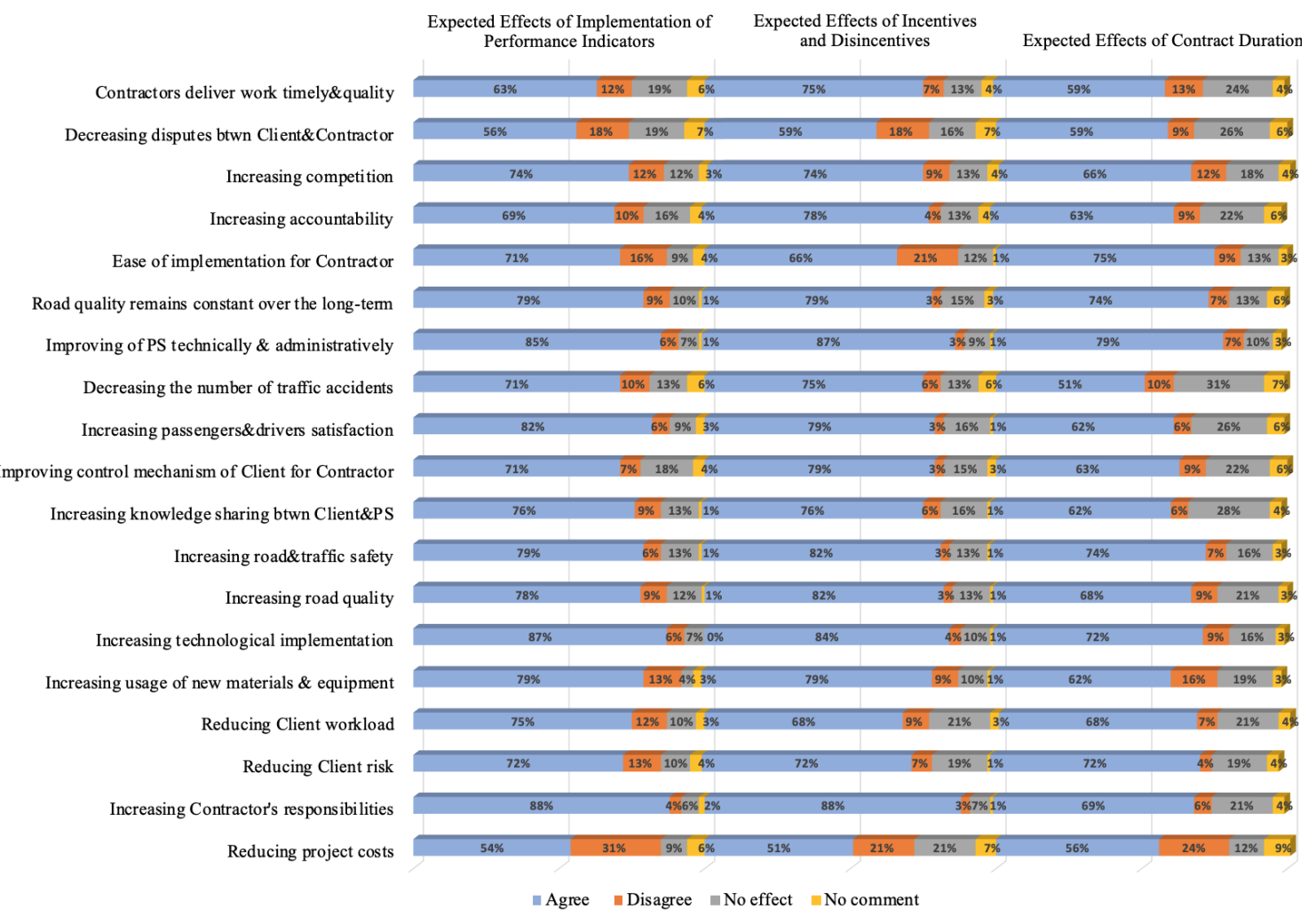

Fig. 6. Effects of PBC

If $\mathrm{PBC}$ is adapted to the current system, potential effects of performance indicators, which are among the most effective features of $\mathrm{PBC}$, were asked to road experts. More than $50 \%$ of the experts 
agreed that performance indicators would create a positive effect on RM services, including time, quality, accountability, and safety. More than $80 \%$ of the road experts especially concurred that PBC would increase contractor's responsibilities, technological implementation, passenger \& driver satisfaction, and improve private sector technically $\&$ administratively. Potential effects of incentive \& disincentive system and long-term contract duration, which are the other distinctive characteristics of PBC, were also asked to the road experts. More than $50 \%$ of the experts stated that these characteristics would have positive effect on all features.

RM services are generally carried out either by in-house or private sector globally. Similarly, 78\% of the road experts expressed that RM services must be executed by both the private sector and road authorities, as it is in Turkey in the current practice.

Organizations, like European Union Road Federation (ERF) are making efforts to implement Road Management System all over the world and studying significant effects on RM services. Road experts were asked to evaluate the possible effects of using Road Management System in Turkey. The list of criteria listed in Fig. 7 was identified from the
ERF report. More than $80 \%$ of the experts' responses agreed on the positive effects if the system is adapted in Turkey. The highest negative impact ( $6 \%$ of participants) is observed for the reduction in user costs. Overall, road experts were more convinced that Road Management System would improve the management and monitoring of the inventory, data, and services.

Participants were also asked "Are the road maintenance services executed in Turkey needed to be improved and $96 \%$ of road experts consider that current RM services should be improved in Turkey. Furthermore, participants are also asked "Whether the current negative conditions of RM services in Turkey could be addressed by PBC", 50\% of the experts answered 'partially agree', and $37 \%$ of the experts answered 'agree'. When considering participants having experience more than 21 years in the road construction area, it understood that they would like to further improve this system with different solutions.

Finally, open-ended questions were asked to road experts to understand the status of existing RM services, and to get their opinions and recommendations for developing the current system.

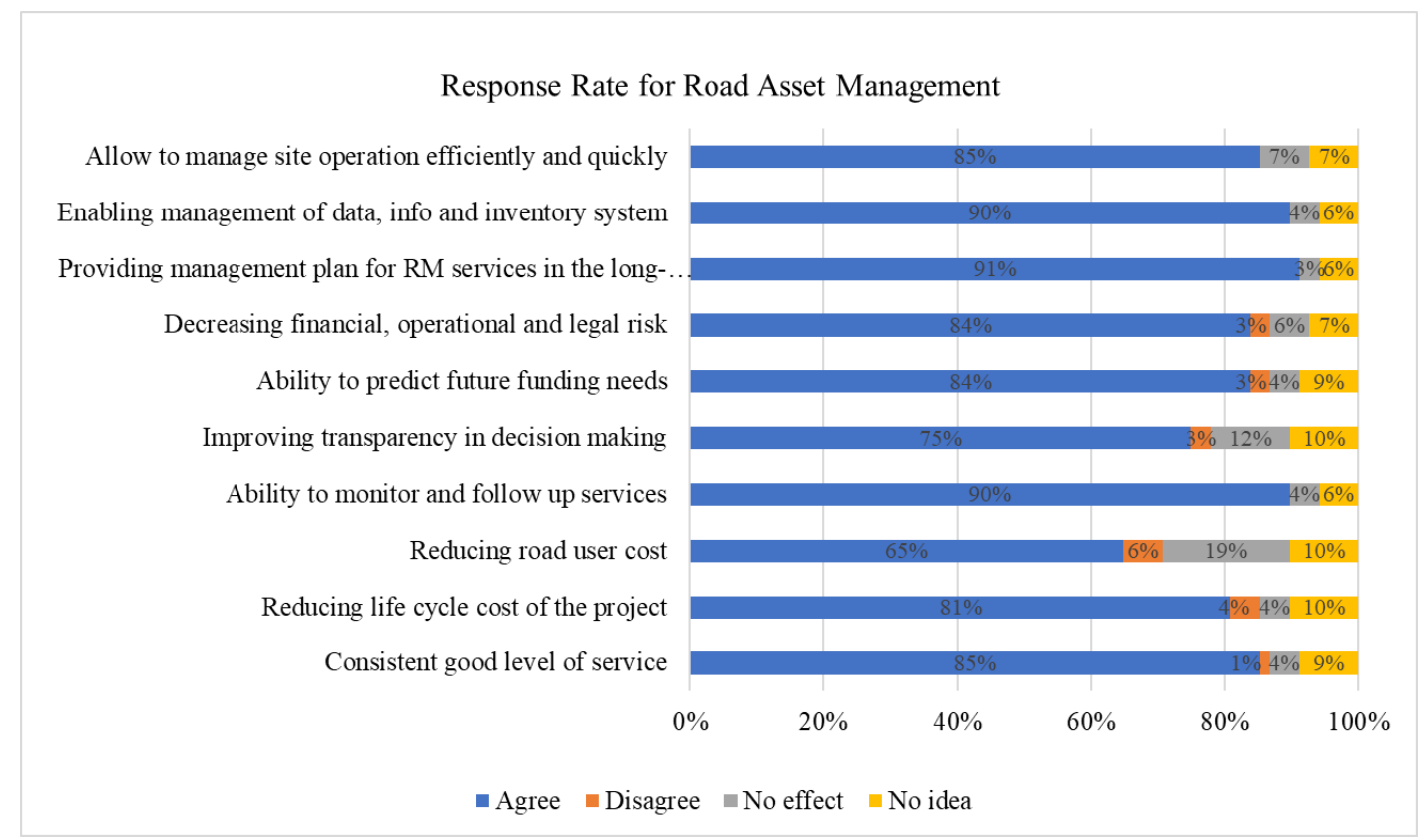

Fig. 7. Assessment of road asset management 
Comments were integrated and summarized regarding different points such as organizational structure and training, cost of projects, traffic and road safety, snow and ice removal works, contract duration, implementation methods, quality and innovative technics, contractual issues and parties' responsibility. The most frequent and prominent points were as follows:

- Current RM services in Turkey have shortcomings in terms of both contractual and executive issues.

- Permanent solutions should be produced in the long term to address existing shortcomings.

- Road quality should be improved.

- Contractors' technical and financial capability should be evaluated in the tender stage.

- Pre-qualification phase should be preferred during the tendering process

- Technical approach and methodology of contractors for project should be evaluated in the tender stage.

The most common and highly emphasized comment of road experts was that performance indicators and incentives and disincentives system should be implemented to ensure road quality. Road experts' recommendations suggested improvements that can be acquired if PBC is implemented in Turkey, and these suggestions could eliminate the existing deficiencies. Overall, both the road users and road experts agreed that there is positive and high potential to improve the current RM services through the application of PBC.

As aforementioned earlier, Gun (2014) conducted a study to examine the current RM services and applicability of PBC in Turkey. Since the target audience of that survey was the GDH employees, the results were one-sided. However, the viewpoints of all stakeholders (e.g., users, designers, consultants) should be acquired to draw a holistic picture. Hence, the results of the Gun (2014) were compared with the results acquired in this study. Consistent and similar perspectives were identified regarding the potential benefits of applying PBC for Turkish RM sector. However, differences regarding the ease of implementation of
PBC and the current status of RM services were observed. In other words, the participants of the survey in 2014 were more satisfied with the RM services and participants of 2019 survey considered PBC easier to implement. Such differences can be caused due to the target audience or the change in opinions or awareness over the years.

\section{Conclusion}

Turkish Ministry of Transport and Infrastructure within the scope of 2023 strategy plan targets to expand the roadway network [5]. Therefore, the condition of the existing network and the expected construction of new roads will lead to an increase in the RM services in the near future. Regarding this issue, a well-planned, organized, and prospective strategy for RM is required to manage the limited funds and to sustain a high road quality in the longterm. Due to such issues, PBC, a contracting type for RM services, has become prominent in the world. Many developed countries have been successfully implementing PBC. Besides, many developing countries are performing pilot studies to evaluate PBC for RM Services. The purpose of this study was to investigate the RM services in Turkey and to examine the applicability of PBC for the Turkish RM sector.

Within the scope of this study, a detailed literature review has been carried out regarding a) the importance of road maintenance, b) the implementation of road maintenance services in Turkey, and c) the historical development, characteristics, advantages, and challenges of PBC in road maintenance. Accordingly, the RM services executed in Turkey, its shortcomings, and the potential of $\mathrm{PBC}$ to address these shortcomings were examined by means of interviews and surveys. Interviews with senior road experts were performed to develop survey questions. Then, two sets of surveys, one for the road experts and the other one for the road users, were prepared. A total of 1036 road users and 71 road experts participated in this study. Indeed, 3 road experts from different stakeholders in the road sector shared their perceptions, comments, and recommendations 
through interviews, and similarly, 68 road experts from different parties participated in the survey.

According to perceptions and comments of 1036 road users for existing RM in Turkey, the current RM services are not satisfactory, affecting mostly the road safety. According to the perceptions of road experts, the existing RM services must be improved by changing the existing contracts. Particularly, the identification of performance indicators and the usage of incentives/disincentives system, which are the main characteristics of PBC in RM works, are recommended. These modifications could partially lead to overcome the deficiencies of the current RM services. Therefore, road experts are quite positive for using $\mathrm{PBC}$ in Turkey. Moreover, Road Asset Management system suggested by ERF should be developed and implemented to provide a sustainable and effective strategy for the road network and its maintenance for future benefits.

While this study highlights the perceptions of road experts and users on the existing RM services and the need for implementing PBC, a pilot study should be performed to assess the process and feasibility of such a transition. Moreover, to develop Road Asset Management, an inventory study should be carried out by GDH for all road network including road structures in Turkey. Finally, following the path of the successful PBC implementations, road agencies in collaboration with other parties should identify performance indicators and develop new contracting types such as $\mathrm{PBC}$ to reduce the deficiencies and enhance the quality of RM services.

\section{Ethics committee permit and/or legal/special permission}

The authors acquired ethics committee permission for surveys implemented in this paper from the Human Subjects Ethics Committee of METU (No. 350 ODTÜ 2019).

\section{Declaration of conflicting interests}

The author(s) declared no potential conflicts of interest with respect to the research, authorship, and/or publication of this article.

\section{References}

[1] Burningham, S, Stankevich, N (2005) Why road maintenance is important and how to get it done The World Bank, Washington DC Transport Note No. TRN-4 June.

[2] Levik K (2001) How to sell the message "Road maintenance is necessary" to decision makers. In First Road Transportation Technology Transfer Conference in Africa.

[3] Hancher DE (1999) Contracting methods for highway construction. TR News, 205(1), 10-15.

[4] Asian Development Bank. (2018). Guide to Performance-Based Road Maintenance Contracts.

[5] General Directorate of Highways Statistics. (2019). Retrieved from http://www.kgm.gov.tr/Sayfalar/KGM/SiteTr/Roo t/default.aspx.

[6] Gün B (2014) Karayolu Bakım-Onarım Hizmetlerinde Performans Esaslı Sözleşmelerin Uygulanabilirliği.

[7] Zietlow GJ (2007) Performance-based road management and maintenance contracts-worldwide experiences. In International Seminar on Road Financing and Investment (pp. 1-76).

[8] Pakkala P, Martin de Jong W, Aijo, J (2007) International overview of innovative contracting practices for roads.

[9] Al-Kathairi A (2015) Performance Based Road Asset Management System, with a case study: Abu Dhabi (Doctoral dissertation, Carleton University).

[10] Sultana M, Rahman A, Chowdhury S (2012) Performance Based maintenance of road infrastructure by contracting-A challenge for developing countries. Journal of Service Science and Management, 5(02), 118.

[11] Selviaridis K, Wynstra F (2015) Performancebased contracting: a literature review and future research directions. International Journal of Production Research, 53(12), 3505-3540.

[12] Ozturk HI, Atasoy G, Ates K (2018) A Strategic Plan for the Implementation and Monitoring of Performance-based Maintenance Contracting (PBMC) for Turkish Construction Sector, 13th International Congress on Advances in Civil Engineering 12-14 September 2018, İzmir, Çeşme. 
[13] Gajurel A (2014) Performance-based contracts for road projects. Comp. Anal., 1-159.

[14] De la Garza JM, Pinero JC, Ozbek M E (2009) A framework for monitoring performance-based road maintenance contracts. In Proceedings of the Associated Schools of Construction 45th Annual International Conference,, Gainesville, FL (pp. 433-441).

[15] Stankevich N, Qureshi N, Queiroz C (2005) Performance-based contracting for preservation and improvement of road assets. Transport Note No. TN, 27.

[16] Anastasopoulos PC, McCullouch BG, Gkritza K, Mannering FL, Sinha KC (2009) Cost savings analysis of performance-based contracts for highway maintenance operations. Journal of Infrastructure Systems, 16(4), 251-263.

[17] De la Garza JM, Arcella JL (2013) Current Performance-Based Maintenance Methods to Improve Virginia Highways: Comparative Analysis. Transportation Research Record, 2361(1), 35-43.

[18] Zietlow G (2005) Cutting costs and improving quality through performancebased road management and maintenance contracts-the Latin American an OECD experiences. Senior Road Executives Programme, Restructuring Road Management, German Development Cooperation, Birmingham.

[19] Sultana M. The Potential of Performance Based Maintenance Contracting for Road Infrastructure Systems of Developing Countries. MSc thesis, Griffith University, Queensland, Australia, 2012.

[20] Ahmed J, Gharaibeh NG, Damnjanovic ID (2012) Best-value bid selection methods for performancebased roadway maintenance contracts. Transportation Research Record, 2292(1), 12-19.

[21] Madelin K, Parkman CC (1999) A review of contract maintenance for roads. In Konferenzbeitrag, World Road Congress, World Road Association (PIARC), Paris.

[22] Ates K. Assessment of Applicability of Performance-Based Contracts in Turkey for Road Maintenance Services. MSc thesis, Middle East Technical University, Ankara, Turkey, 2019.

[23] Israel GD (2009) Determining Sample Size. University of Florida, IFAS Extension. 